\title{
Ageing population and labour productivity in Bulgaria
}

\begin{abstract}
Recent literature has shown that it is difficult to ascertain the impact of an ageing population on labour productivity. According to the majority of studies, workforce ageing leads to lower employment and a decline in the professional skills of the employed, so we should expect that it has a negative impact on technological changes and productivity. In this article, we present a review of studies on this issue. After that, an empirical study for Bulgaria is provided using sensitivity tests of long-term projections of labour productivity (to 2050), based on population number and age distribution. A model of the International Labour Organisation (ILO) is applied which allows us to calculate three variants of changing age, number and structure of population, assuming three different rates of improvement in life expectancy - fast, medium and slow. The study confirms that an ageing population has a negative effect on labour productivity. The timeframe is long but, with that limitation in mind, the overall direction of the trend is clear. The article concludes with some policy considerations to help ameliorate the effects of Bulgaria's demographic challenge.
\end{abstract}

Keywords: populating ageing, labour productivity, de-population, working age population, unemployment, life expectancy, age dependency ratio

\section{Introduction}

In practice, there are several main channels through which population ageing affects the economy: decreasing labour supply; declining savings; and increasing healthcare and pensions expenditures. An increasing share of the elderly in the total population poses overall macroeconomic problems in terms of financing the associated inter-generational transfer of resources. ${ }^{1}$ According to the life-cycle hypothesis of savings, older people are expected to spend their accumulated savings so that the total amount of savings available to the economy will decline. These demographic changes will, therefore, affect future economic development.

An ageing population will have an impact not only on public finances, but also labour productivity. It is evident that future technological progress in developed countries will be realised by a smaller and older workforce. By assumption, the latter leads to lower income per capita for at least two reasons: first, the increasing share of the older population changes the proportion between producers and consumers; second,

1 Rangelova, R (2002) 'Bio-Demographic Change and Socio-Economic Trends in Bulgaria' Economics and Human Biology 31(3): 413-428. 
the relatively older population has a negative impact on economic productivity. Estimating the precise magnitude and direction of these impacts over time, and the way they will interact, is a complex and difficult task.

The great challenge for countries experiencing a rapidly ageing population is to retain their competitive advantages over other states. In particular, the question is what impact this process will have upon aggregate labour productivity, defined as GDP per employee.

The article is organised as follows. Firstly, the theoretical framework and a review of the recent literature are presented; and then, secondly, an empirical study for Bulgaria is provided, using a sensitivity analysis of labour productivity based on long-term projections (up to 2050) for the population and its age distribution.

\section{Theoretical framework and literature}

There is a vast number of studies attempting to model the impacts of an ageing population and (not surprisingly) the findings are very diverse. Up to now, there has been no definite consensus about the effect of an ageing population on labour productivity. According to the predominant view, workforce ageing leads to a reduction in the number and quality of employed people and, for this reason alone, we should expect that it will have a negative impact on technological change and productivity. The emerging gap between labour demand and supply will, furthermore, provoke tension in the labour market. Another common argument is that an ageing population is likely to be less entrepreneurial and ambitious, and may, therefore, negatively affect economic growth.

The European Union (EU) employment rate for the population aged 55 to 64 is generally low. At $46.0 \%$ in 2009, the EU-27 is still behind the Stockholm target of $50 \%$ (it is $62 \%$ in the USA and Japan). Extending working life (by re-thinking retirement and enforcing employability up to the age of 65-67) by improving incentives and opportunities for older workers has become a priority in the EU in order to mitigate the impact of the ageing of the population on labour supply and retirement systems. Extending working lives and delaying retirement through policies that promote active ageing was one of the priorities in the revised European Employment Strategy for the period 2003-2010 and such initiatives now take their place in the strategy Europe $2020 .^{2}$ European governments are committed to improve the labour market position of older workers.

The changing age structure is expected to have an unfavourable impact upon the capability of the workforce to adapt to technological change and to obtain new skills through adaptability and the sharing of a few professional skills. This new economic reality requires a new life-cycle educational pattern, including life-long learning, increased knowledge of foreign languages, computer skills, adaptability to new economic conditions, etc. However, all these qualities are not intrinsic in older people but are more typical of young people who are more dynamic, more adaptive to new technolo-

2 See The Future of the European Employment Strategy (EES) A strategy for full employment and better jobs for all COM(2003)6(01) http://ec.europa.eu/europe2020/priorities/inclusive-growth/ index en.htm. 
gies, more ambitious and who have greater physical endurance. There is another argument that older workers are more expensive than younger ones because of senioritybased remuneration systems, additional social benefits and so on. The problem is that the relative price of older workers will rise even though its quality might decline, which will further reduce the competitiveness of ageing economies (Laezar, 1990). ${ }^{3}$

A more intensive exploration of the impact of an ageing population on labour productivity began in the early 1990s (see Appendix). These publications can be separated into several groups. Some of them analyse the impact of an ageing workforce on labour productivity at the level of the individual or firm (Laezar, 1990; Johnson, 2002; Auer and Fortuny, 2002; Skirbekk, 2004). In particular, this literature considers the potential interaction between cohort effects, age effects and other productivity effects (including company-specific production processes and organisational structures) which complicates the uncovering of the pure age effect on individual productivity.

The relationship between age and individual productivity is not clear, but there is evidence of a significant relationship between changes in the age structure of the adult population and aggregate productivity. The second group of papers includes studies at a macro level, which may be sub-divided in relation to methodology. Some authors use the Solow production function, encompassing the idea of total factor productivity (TFP), to account for the effect of the age structure of the workforce on aggregate labour productivity (Malmberg, 1994; Prescott, 1998; Feyrer, 2002; Koegel, 2004). In general, their results confirm the negative productivity impact of an ageing workforce. The study by Beaudry and Collard (2003) relates closely to the empirical evidence which has shown that input accumulation cannot explain the majority of cross-country differences in output per worker, but that the 'residual' (and, therefore, TFP) must account for the differences (see Prescott, 1998: 525-552).

Carone et al. (2006) present the results of long-run labour productivity and GDP growth rate projections (to 2050) for each of the $25 \mathrm{EU}$ member states and provide a detailed overview of the forecast methodology used. The authors use a common production function methodology for all 25 countries and show the GDP growth rate effects of an assumptions-driven extrapolation of recent trends in employment and labour productivity. Various sensitivity tests are carried out to check the GDP per capita impact of some factors which have been excluded from the baseline scenario either for reasons of simplicity or because of a lack of consensus in the academic literature. The result is that these sensitivity tests allow the authors to draw some interesting conclusions (see Appendix).

The results of Beaudry and Collard (2003) imply that a country having a yearly growth rate in the adult population of $1 \%$ greater than the average level would experience lower growth in output per worker of approximately $1 \%$ which, compounded over 22 years, corresponds to a difference of $25 \%$ in labour productivity. These results are similar to earlier findings in Cutler et al. (1990) from a sample of 29 countries whose labour productivity was at least $30 \%$ of that of the USA. They found that a one percentage point decrease in the annual growth rate of the workforce raised productivity growth by 0.62 percentage points per year between 1960 and 1985 .

3 For the authors quoted in this review of the literature, see the Appendix. 
Other authors use the new endogenous growth theory. For example, Dalgaard and Kreiner (2001) present a theoretical framework which implies that even a dramatic decline in population growth will not lead to a long-term slowdown in labour productivity. The authors study the endogenous impact of human capital in a basic R\&Ddriven growth model and develop a theory of scale-invariant endogenous growth where population growth is neither necessary for, nor conducive to, economic growth.

Most studies of the economics of ageing assume perfect substitutability among workers at different ages without discussing alternative labour demand functions.

Also many researchers realise that, by focusing on labour and ignoring physical capital, they disregard one of the most important channels through which the negative impact on productivity of labour force shrinkage may be attenuated. It is well-known in neoclassical growth theory that population decline increases the steady state capitallabour ratio since fewer people have to be equipped with capital. These effects are captured in general equilibrium models which constitute the theoretical framework for studying the economic consequences of population ageing. Most of those models, however, are restrictive in that the assumed production technology, in most cases, aggregates workforce of all ages into one factor (Lam, 1989: 189-210).

Fuernkranz-Prskawetz and Fent (2004) aimed to introduce imperfect substitutability across age cohorts in the labour market and to consider the implication of this for economic productivity during times of rapid labour force shrinkage and ageing. In other words, they investigate the time path of economic productivity in a pure labour economy where workers of different ages are not perfect substitutes. The authors present simulations and analyse the sensitivity of projected labour productivity with respect to alternative assumptions about future labour supply and the substitutability and productivity of the workforce at different ages. The simulations are based on official population projections for the Austrian population covering the time interval between 2000 and 2075 , and on the basis of workforce participation rates provided by the OECD. The authors discuss trends in the support ratio (the number of active workers in the dependent population). They apply alternative assumptions about the substitutability, productivity and labour supply of workers of different ages in order to calculate alternative economic productivity scenarios. One of their main findings is that:

In a pure labour economy, the assumption of imperfect substitution of workers at different ages implies an increase in relative economic productivity during the next two decades compared to a constant or declining economic productivity that results in case of the commonly applied additive labour demand function found in the literature. (Fuernkranz-Prskawetz and Fent, 2004: 142)

They recommend that future studies verify the robustness of their results with respect to the inclusion of non-labour factors in production functions and focus on estimating the elasticity of substitution between workers at different ages and how this may change over time as technological progress advances.

The relationship between an ageing population and labour productivity differs across economic sectors and activities. It also differs by individual profession or occupation. There are jobs for which physical strength or stamina are important, like builders, constructors, drivers, etc. where young workers are at an advantageous pos- 
ition. In other occupations, like IT specialists, where mental acuity and being up on the latest technical innovations are crucial, young workers are also at an advantage. The situation is different in those occupations where experience and investment in knowledge over time are important, like scientists, medical doctors, lawyers, journalists, politicians, engineers, architects, people in fine arts, etc. In these latter areas, the experience and expertise gained throughout a long-lasting professional career are definitely more important than traits which are inherent to newcomers. Older workers here could be at an advantage. Productivity in some sectors and activities like science is not hindered by age. Moreover there is no retirement age in politics, so why is the age of retirement still in place for scientists? ${ }^{4}$

Age variation in cognitive (and mental) abilities is likely to affect productivity levels, because it is one of the most important determinants of success in education and on the job. Skirbekk (2004), for instance, focused on how individual productivity varies by age. The causes of productivity variations over the life-cycle depend on how cognitive abilities affect labour market performance. One of the main findings is that individual job performance decreases after around fifty years of age, which contrasts with almost life-long increases in wages. Productivity reductions at older ages are particularly strong for work tasks where problem solving, learning and speed are needed, whereas in jobs where experience and verbal abilities are important older workers are at an advantageous position.

The ageing process can be examined as a factor contributing to structural changes in the economy which, in its turn, leads to changes in aggregate labour productivity. There is empirical evidence that an increase in the share of elderly workforces (at the expense of the share of young people) positively affects employment shares in community, social and personal services as well as in the financial sector (Kholodilin, Siliverstovs and Thiessen, 2011).

The productivity of individuals doing 'creative' jobs, such as researchers (within physics, geology, physiology and biochemistry), authors and artists, is measured by many authors in terms of the quantity and, sometimes, the quality of their output. Most of these studies found that a researcher's output is negatively associated with the researcher's age. Similar evidence is found in the field of economics (Oster and Hamer-

4 There is a general feeling in most European universities that, when you retire (at 65), you should retire to make way for new people. This is the case of the immunologist Klaus Rajewsky (currently aged 74), who retired from the Max Delbrück Centre but who wanted to continue his research. Consequently, he moved across the Atlantic to the Harvard Medical School in Boston, Massachusetts where he took up a position 'without time limit' - dependent only on obtaining research grants. Meanwhile, German universities have changed their policy, in particular the rules of retirement. Those who are over the traditional retirement age and who want to continue research, and can demonstrate that they are competent, may be offered opportunities of good positions. If they really want to research, they can find a way. Klaus Rajewsky was the first to take advantage of this and returned to his own country, but there are also negotiations taking place with other specialists who may be persuaded to return, at least at the Max Delbrück Centre (see 'German science benefits from pensioner power' 23 December 2010 Nature online magazine http://www.nature.com/news/2010/101223/full/news.2010.696.html [last accessed 12 February 2012]). 
mesh, 1998), where the authors conclude that older economists publish in leading journals less than younger ones and that the rate of decline is the same for top researchers as others.

Regarding individual profession, perhaps the most radical opinion in favour of ageing researchers' confirmed labour force participation was expressed by Nobel Prizewinning economist Gary Becker. He wanted to know whether the 1994 end of mandatory retirement for professors in the US would lead to less innovation. He points out that the:

Analysis of dozens of studies of scholarly productivity suggests that such fears are overstated.

He begins with a survey of studies of IQ, concluding that, while cognitive ability does decline after 67 , the trend is quite modest until 80 and that many 80 -year-old scholars do not show significant deterioration. Becker notes that studies of:

Scholarly productivity over the life-span are more inconclusive than conventional wisdom suggests.

Certain studies from the 1970s and 1980s did find that productivity peaked between 35 and 44. Nevertheless, others, including a 2006 study of members of the US National Academy of Sciences, showed a resurgence in output after 60 . And the research does not often take into account structural incentives. Experience in Norway shows that scholars at 60 and over used to slack off but, after Norway raised publication standards for all its professors, they surpassed some younger cohorts. ${ }^{5}$

\section{Empirical study of Bulgaria}

Long-term projections of demographic indicators

According to all the known projections for Bulgaria produced by international organisations (UN, World Bank, Eurostat, etc.), national institutions (like the National Statistical Institute in Sofia) or individual authors, de-population will continue and even accelerate. The de-population process will be accompanied by a continuously ageing population. An unfavourable implication of the change in the age structure is a considerable reduction in the working-age population.

The periodic population projections carried out by the UN are perhaps those mostused by analysts because of the well-developed methodology and the wide number of included countries (over 200). The data presented in these reports cover estimated sex and age distributions from 1950 until the present day and give projections by high, medium and low variants for the years up to 2050. Most of the estimates presented

5 'Week in ideas' at online.wsj.com, 16 October 2010. The paper quoted concludes thus: 'It may be the European system, which still has mandatory retirement (at 65 or 67), that is the ideasquelcher.'

http://online.wsj.com/article/SB10001424052748703673604575550071622397954.html [last accessed 12 February 2012]. 
there are derived from available national data that have been evaluated and adjusted (if necessary) for deficiencies and inconsistencies. ${ }^{6}$

For the purposes of the present study, a model of the International Labour Organisation (ILO) is applied. ${ }^{7}$ Its logical structure allows answers to questions related to health policy goals and strategies. The ILO model includes the most important national variables (indicators for population development, employment, the insurance system, government budget, etc.) related to healthcare expenditure and their combined influence on it. ${ }^{8}$

A sensitivity test was used to check the reliability of the model results. For each test, the value of one parameter was changed and the results compared with the status quo projection. We used a test built on three alternative variants of the changing age structure in the country up to 2050, assuming different improvements in life expectancy at birth - at fast, medium and slow rates. The second variant, reflecting a medium pace of improvement in life expectancy at birth, is used as a baseline scenario in this article. The base year for calculations is 2008 , which was chosen because it is the last year when Bulgarian economic performance was not influenced by the global financial crisis.

Following the 1960s, and in particular since 1990, Bulgaria's population has aged considerably and now ranks among the five countries in the world with the largest share of the population over 60 . The main determinants of the accelerated rate of ageing are a falling birth rate, declining mortality and longer life spans. Another important factor driving the ageing population in Bulgaria is large-scale emigration, leading to a negative net migration balance. ${ }^{9}$

Projections of Bulgaria's population for the purposes of the ILO model applied here are taken from the aforementioned UN source. These projections also predict the continuing de-population of Bulgaria (Table 1). According to these projections, Bulgaria's population will decrease by roughly 1.4 million - from nearly 7.6 million in 2008 to 6.2 million to 2050 . This trend will be caused by the death rate exceeding the birth rate, resulting in an increasing negative natural rate of population growth. The fertility rate shows an increasing trend in the long-term (from 1.57 in 2008 to 1.89 in 2050), but it remains below the replacement level of 2.1 .

Considering the old age population by ethnic group, Bulgarians strongly dominate everyone else. Official data show that Bulgarians, being $83.9 \%$ of the total population, comprise $90.4 \%$ of the population aged $60-69$ and $92.4 \%$ of that aged 70 and over. Turkish people account for $9.4 \%$ of the total population and comprise $6.7 \%$ of the

6 The Sex and Age Distribution of the World Population, UN World Population Prospects 2001 Revision Department of Economic and Social Affairs Population Division: New York.

7 The basic features of the model could be found as described in: Cichon, M et al (1999) Modelling in Health Care Finance. A compendium of quantitative techniques in health care financing International Labour Organisation, International Labour Office: Geneva. The model is realised using Microsoft Excel.

8 Rangelova, R. and G. Sariiski (2007) 'Long-term Projections of Health Care Expenditure in Bulgaria' Economic Studies 2: 27-57. Series of the Institute of Economics, Bulgarian Academy of Sciences and the Economic Academy 'D. Tsenov': Svishtov.

9 Population migration is not taken into account in the ILO model. 
$60-69$ population and $4.9 \%$ of that which is $70+$, while Roma account for $1.5 \%$ and $0.8 \%$ of the respective populations.

The female elderly population outnumbers that of the male, as the share of women aged between 60 and 79 is nearly $60 \%$. The male/female proportion favours the female population in the long-term as well (Figure 1).

Table 1 - Demographic indicators for Bulgaria, 2008, and projections for 2025 and 2050 (medium improvement in life expectancy)

\begin{tabular}{|l|c|c|c|}
\hline & $\mathbf{2 0 0 8}$ & $\mathbf{2 0 2 5}$ & $\mathbf{2 0 5 0}$ \\
\hline Population, total (000) & 7,580 & 7,172 & 6,205 \\
\hline Male & 3,658 & 3,465 & 3,000 \\
\hline Female & 3,921 & 3,706 & 3,204 \\
\hline Total fertility rate & 1.57 & 1.76 & 1.89 \\
\hline Life expectancy at birth (yrs) & 73.5 & 76.7 & 79.7 \\
\hline Male & 69.9 & 73.4 & 76.7 \\
\hline Female & 77.1 & 80.0 & 82.7 \\
\hline Crude birth rate (per 1 000) & 10.2 & 8.4 & 9.7 \\
\hline Crude death rate (per 1 000) & 14.5 & 13.6 & 16.2 \\
\hline Natural increase (per 1 000) & -4.3 & -5.2 & -6.5 \\
\hline Population growth, \% & -0.10 & -0.52 & -0.65 \\
\hline
\end{tabular}

Figure 1 - Number of population in Bulgaria, 2008, and projections to 2050, medium improvement in life expectancy

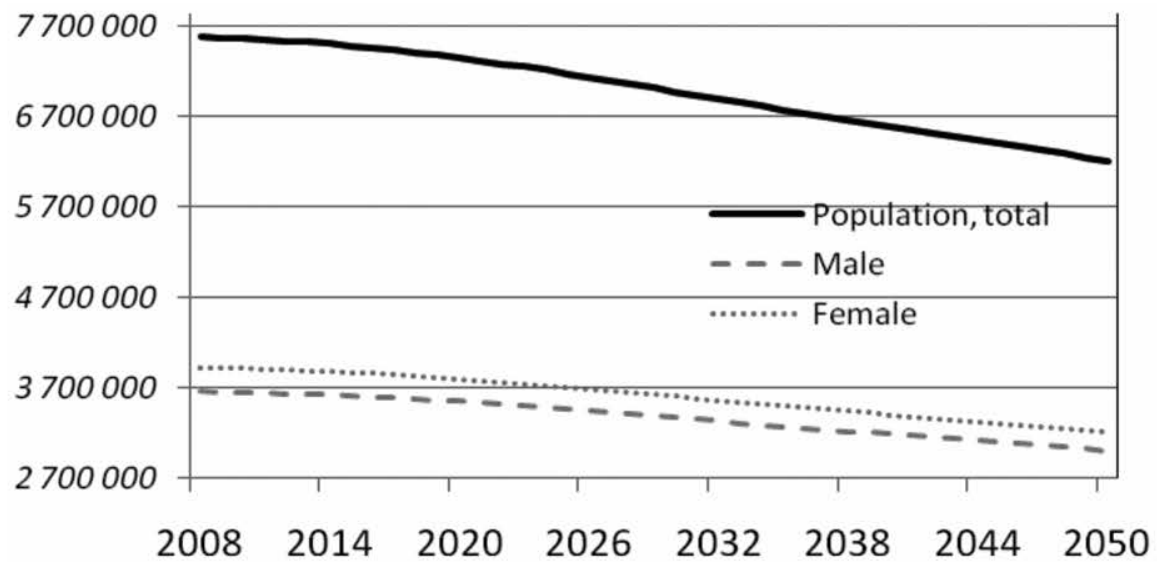


Life expectancy in Bulgaria is relatively low in comparison with other EU member countries: for the 2007-2009 period, total life expectancy at birth is 73.5 years; for men it is 69.9 years and for women it is 77.1 years (Table 2).

We present in Table 2 the three variants of life expectancy until 2050. According to the first variant (rapid improvement), life expectancy for both sexes will increase by nearly 7.5 years, while according to the third variant (slow improvement) it will increase by 4.6 years. All three variants indicate that female life expectancy will surpass eighty years, but male life expectancy will even get close to eighty years only under the first variant. However, it will not reach current female life expectancy under the second and third variants.

Table 2 - Life expectancy in Bulgaria, 2008, and three projected variants to 2050

\begin{tabular}{|c|c|c|c|c|c|c|c|c|c|}
\hline & 2008 & 2015 & 2020 & 2025 & 2030 & 2035 & 2040 & 2045 & 2050 \\
\hline \multicolumn{10}{|c|}{ I variant - fast improvement of life expectancy } \\
\hline Total & 73.5 & 75.3 & 76.3 & 77.3 & 78.2 & 79.1 & 79.8 & 80.5 & 81.0 \\
\hline Male & 69.9 & 71.9 & 73.0 & 74.0 & 75.0 & 75.9 & 76.7 & 77.5 & 78.2 \\
\hline Female & 77.1 & 78.7 & 79.7 & 80.6 & 81.4 & 82.2 & 82.9 & 83.4 & 83.9 \\
\hline \multicolumn{10}{|c|}{ II variant - medium improvement of life expectancy } \\
\hline Total & 73.5 & 75.0 & 75.9 & 76.7 & 77.5 & 78.1 & 78.7 & 79.2 & 79.7 \\
\hline Male & 69.9 & 71.5 & 72.5 & 73.4 & 74.2 & 75.0 & 75.7 & 76.2 & 76.7 \\
\hline Female & 77.1 & 78.4 & 79.2 & 80.0 & 80.7 & 81.2 & 81.7 & 82.2 & 82.7 \\
\hline \multicolumn{10}{|c|}{ III variant - slow improvement of life expectancy } \\
\hline Total & 73.5 & 74.7 & 75.3 & 75.9 & 76.4 & 76.9 & 77.4 & 77.8 & 78.1 \\
\hline Male & 69.9 & 71.2 & 72.0 & 72.7 & 73.2 & 73.7 & 74.2 & 74.7 & 75.1 \\
\hline Female & 77.1 & 78.1 & 78.6 & 79.1 & 79.6 & 80.1 & 80.5 & 80.8 & 81.1 \\
\hline
\end{tabular}

The de-population process will be accompanied by a continually ageing population. Even in 2008, the share of the young population (0-14 years of age) in the total population is lower than that of the old population ( 65 years and over). This indicates that there are more old people in the population than there are young ones. This ratio of the old to the young population will increase and, by the end of the projected period, it is expected that the proportion of the old population will be over twice as high as that of young people.

The second unfavourable change in the age structure in Bulgaria is the considerable reduction in the share of the working-age population (Figure 2). 
Figure 2 - Population age structure, 2008, and projections for 2025 and 2050 , medium improvement in life expectancy (\%)

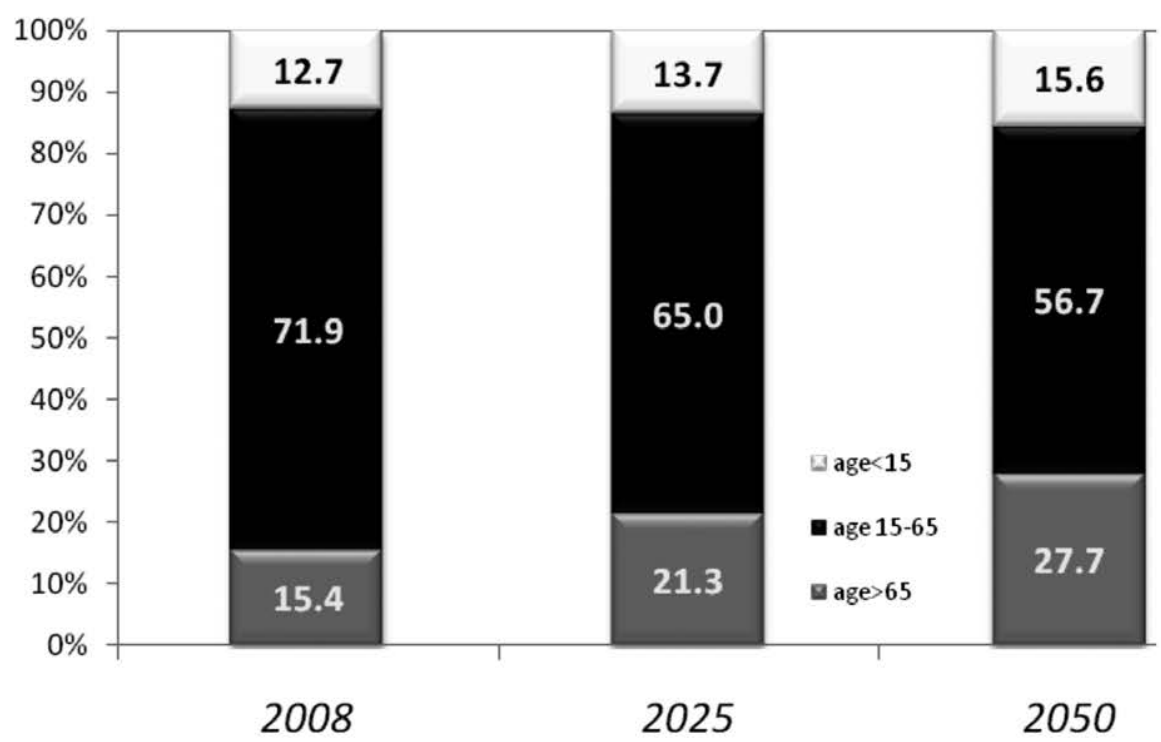

For the population aged 65 and over, the three alternative projections are shown in Figure 3. Evidently, the fastest improvement in life expectancy will lead to the fastest increase in the population.

Figure 3 - Population aged 65 and over, 2008, and projections to 2050 according to the three variants of improvements in life expectancy at birth

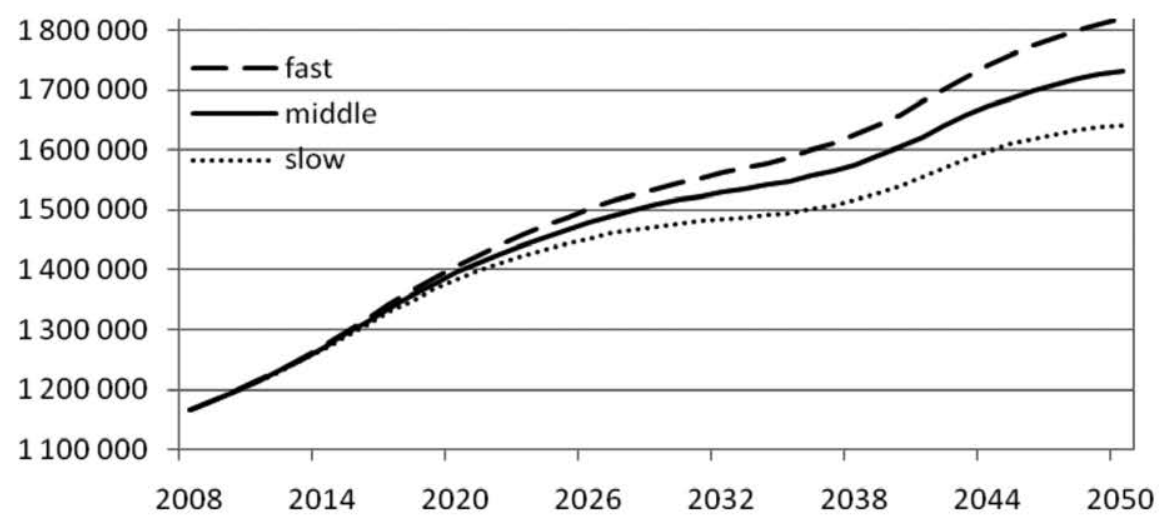

The so-called age pyramid presents the most illustrative picture of the ageing population. The age pyramids for Bulgaria's population in the base year (2008) and the 
main target year for the projections (2050) are shown in Figure 4. In 2008, the age pyramid is narrow at the bottom, which reflects the prior decrease in the youth population. It is expected that this will deepen gradually and will dramatically change the shape of the age pyramid, not only because of the changed ratio between the young and the old, but also because of the reduced proportion of the working-age population.

Figure 4 - Age pyramid in 2008 and projection for 2050
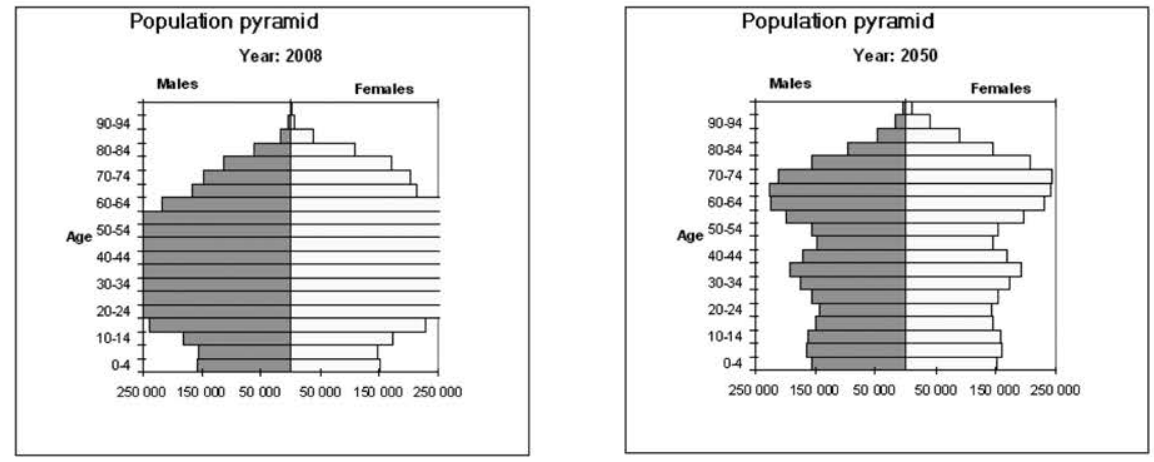

All developed countries, including those in Europe, possess similar demographic profiles and give us further perspectives on the development of the population. The difference is that Bulgaria is among those countries with the fastest rate of de-population.

Extending working lives by delaying retirement through policies that promote active ageing was one of the priorities in the revised European Employment Strategy for the period 2003-2010. ${ }^{10}$ 'Active aging' policies, intended to increase the labour market participation of older individuals, are being encouraged by authorities in most ageing economies. In Bulgaria, the problems are perhaps more difficult in comparison with other EU countries due, on the one hand, to the very rapidly ageing population and, on the other, the relatively low age of retirement up to now. The necessity of improving the incentives and opportunities for older workers in order to mitigate the impact of population ageing on labour supply and retirement systems has not yet been fully organised. This is why the impact of an ageing population on labour productivity is especially important for Bulgaria.

\section{Development of labour market indicators}

The second important group of variables in the ILO model pertain to the labour market in Bulgaria (Table 3). The total population in Bulgaria is accompanied by a decreasing labour force - from 3.6 million in 2008 to nearly 2.2 million in 2050 . These projected trends are illustrated in Figure 5.

10 The Future of the European Employment Strategy (EES) A strategy for full employment and better jobs for all COM(2003)6(01). 
Table 3 - Labour market indicators, 2008, and projections for 2025 and 2050 (\%)

\begin{tabular}{|l|c|c|c|}
\hline & $\mathbf{2 0 0 8}$ & $\mathbf{2 0 2 5}$ & $\mathbf{2 0 5 0}$ \\
\hline Labour force (000) & 3600 & 3103 & 2167 \\
\hline Labour force - annual rate of change & -0.4 & -1.4 & -1.0 \\
\hline Employment rate, total & -0.7 & -1.3 & -1.0 \\
\hline Male & -0.6 & -1.2 & -1.1 \\
\hline Female & -0.8 & -1.5 & -0.9 \\
\hline Unemployment rate, total & 6.6 & 6.3 & 5.3 \\
\hline Male & 6.6 & 5.8 & 6.4 \\
\hline Female & 6.6 & 6.9 & 4.1 \\
\hline
\end{tabular}

Figure 5 - Number of employed people, 2008, and projections to 2050, medium improvement in life expectancy

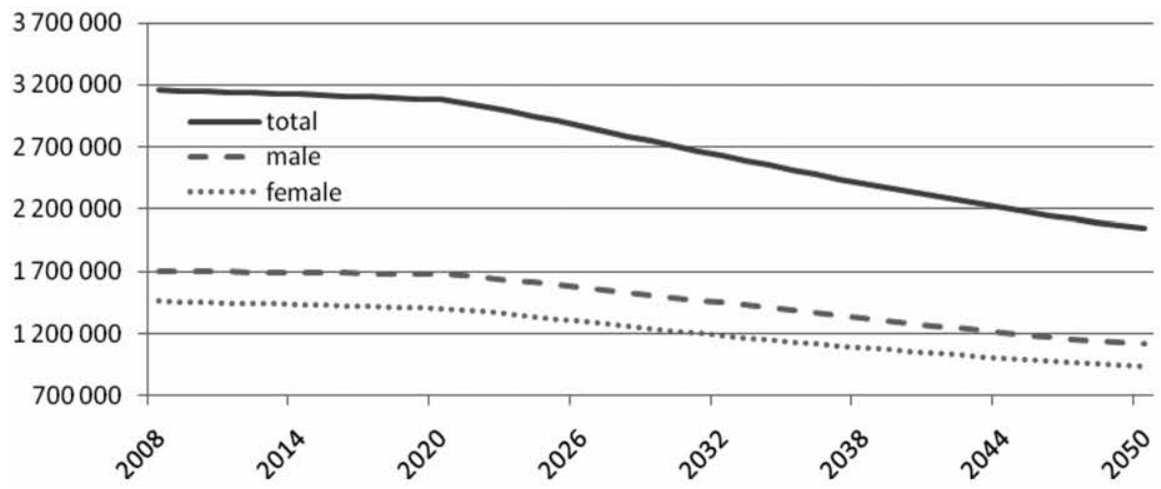

The decline in employment is expected to slow down between 2010 and 2015, something that is related to the effort to diminish the high unemployment rate at the beginning of the $2000 \mathrm{~s}$. After that, however, there is a steady but moderating decrease until 2050, with the highest employment decrease expected to occur around 2025. This trend is connected mainly with the decreasing total population and, in particular, the decline in the working-age population.

The official unemployment rate in Bulgaria showed a very significant decline through the last decade - from $17.9 \%$ in 2000 to $13.7 \%$ in $2002,6.9 \%$ in 2007 and $5.6 \%$ in 2008 (which was lower than the average level in the EU-27). ${ }^{11}$ Due to the

11 In fact, however, regarding the real unemployment level, we should take account also of the so-called discouraged unemployed, of which there is a considerably high number of people (434 500 in 2003 and nearly 150000 in 2008). 
anticipated implementation of a more flexible labour market policy and the development of less restrictive labour market regulations, as well as the proposed faster economic development connected with full membership of the EU, the country experienced sharply-reduced registered unemployment as well as hidden employment. In 2006 , the unemployment rate was already below $9 \%$ (which was on a par with the average for EU countries) and continued its decline. In 2008, the registered unemployment rate was $6.6 \%$ but, due to the global economic crisis, it increased to over $9 \%$ in 2010. According to projections, the unemployment rate is likely to decrease significantly and could reach $5 \%$ by the end of the projected period. This decline is connected implicitly with the assumed comparatively high GDP growth rates over subsequent decades.

Considering the unemployment rate by gender, it turns out that, from equal positions for 2008 (postulated in the ILO model), the female unemployment rate is projected to increase by more comparatively more than the male rate up to 2025 , before decreasing more rapidly than the male rate.

For the purposes of this study, we can use the ILO model to project the number of people at pension age in the labour market for males aged 61 to 70 and for females aged 55 to 70 (Table 4). The three alternative variants show two peaks over the projected period. The highest are the peaks in the first variant - the fast improvement of life expectancy - and the lowest are those of the third variant - the slow improvement of life expectancy (Figure 6). The first peak occurs around 2012 and the second around 2040. The second shows a peak for women a few years earlier than that for men. After that, the number of both elderly men and women who are employed will begin to fall. ${ }^{12}$

Table 4 - Population employed at pension age in 2008 and projections up to 2050 (000)

\begin{tabular}{|c|c|c|c|c|c|c|c|c|c|}
\hline & 2008 & 2015 & 2020 & 2025 & 2030 & 2035 & 2040 & 2045 & 2050 \\
\hline \multicolumn{10}{|c|}{ I variant - fast improvement of life expectancy } \\
\hline Total & 67.6 & 69.6 & 67.6 & 66.6 & 69.2 & 73.5 & 73.9 & 69.9 & 62.0 \\
\hline $\begin{array}{l}\text { Male } \\
(61-70)\end{array}$ & 24.9 & 28.5 & 28.5 & 28.2 & 28.6 & 30.6 & 32.7 & 31.7 & 29.4 \\
\hline $\begin{array}{l}\text { Female } \\
(55-70)\end{array}$ & 42.7 & 41.1 & 39.1 & 38.4 & 40.6 & 42.9 & 41.2 & 38.2 & 32.6 \\
\hline \multicolumn{10}{|c|}{ II variant - middle improvement of life expectancy } \\
\hline Total & 67.6 & 69.5 & 67.4 & 66.3 & 68.9 & 73.1 & 73.5 & 69.4 & 61.5 \\
\hline $\begin{array}{l}\text { Male } \\
(61-70)\end{array}$ & 24.9 & 28.4 & 28.4 & 28.1 & 28.4 & 30.3 & 32.4 & 31.4 & 29.0 \\
\hline
\end{tabular}

12 These results could be influenced by the assumed rates of change in the number of employed people up to 2050 . 


\begin{tabular}{|l|c|c|c|c|c|c|c|c|c|}
\hline $\begin{array}{l}\text { Female } \\
(55-70)\end{array}$ & 42.7 & 41.1 & 39.0 & 38.2 & 40.5 & 42.8 & 41.1 & 38.0 & 32.5 \\
\hline \\
III variant - slow improvement of life expectancy \\
\hline Total & 67.6 & 69.5 & 67.3 & 66.1 & 68.5 & 72.5 & 72.8 & 68.7 & 60.8 \\
\hline $\begin{array}{l}\text { Male } \\
(61-70)\end{array}$ & 24.9 & 28.4 & 28.3 & 28.0 & 28.1 & 29.9 & 31.9 & 30.9 & 28.6 \\
\hline $\begin{array}{l}\text { Female } \\
(55-70)\end{array}$ & 42.7 & 41.1 & 39.0 & 38.1 & 40.4 & 42.6 & 40.9 & 37.8 & 32.2 \\
\hline
\end{tabular}

Figure 6 - Number of employed people at pension age, 2008, and projections to 2050, medium improvement in life expectancy

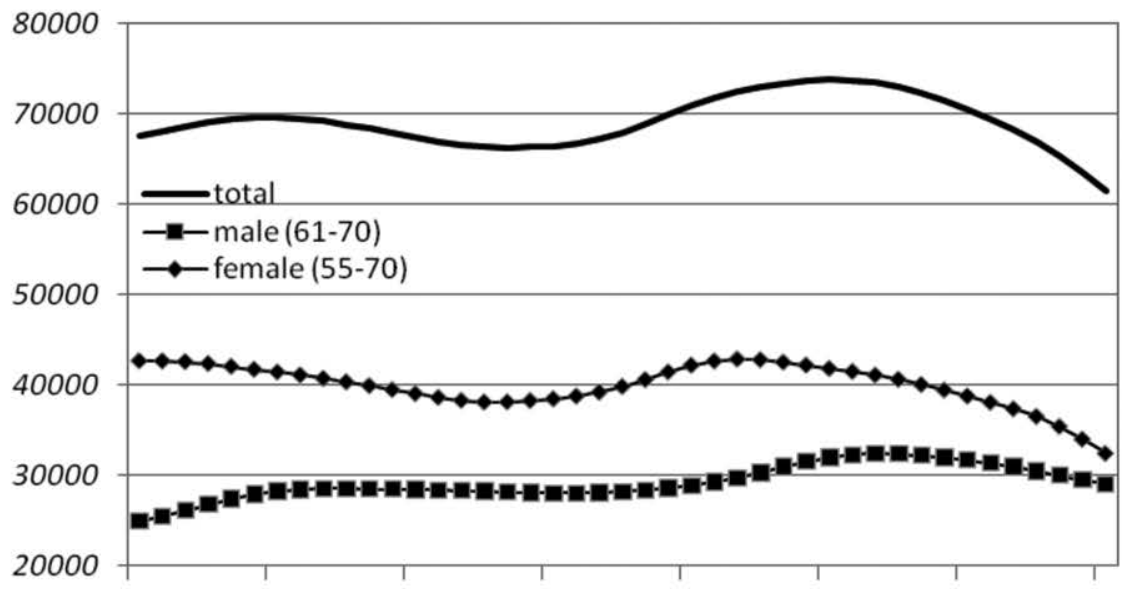

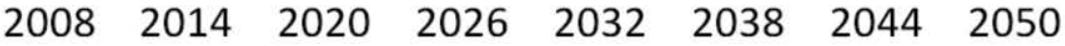

On the basis of the population age structure, we can follow the likely change in dependency ratios, or the economic burden of the working age population - firstly, the child dependency ratio (with children aged up to 14 years); and secondly, the old-age dependency ratio (towards people aged 65 and over). We can also look at the sum of these two age cohorts (Figure 7).

The child dependency ratio is expected to stay almost the same over the long-term, while the old-age dependency ratio will more than double - from $21.4 \%$ in 2008 to $49.3 \%$ in 2050 . The result of these age changes is that the total burden on the working age population is expected to increase from $39.1 \%$ in 2008 to $76.5 \%$ in 2050 . This means that, whereas at present one worker supports nearly half of another person (either a child or an adult), in the long-term up to 2050 the total dependency ratio will be twice as high. This means that one worker will be supporting nearly one other person.

The speed of this process can be projected alternatively, assuming one of the three improvements in life expectancy at birth (Table 5). 
The increasing age dependency ratio reflects the projected future change in the economically active population related to the increasing population of both young and old people. The biggest increases in the dependency ratio are projected assuming either the fastest improvement in life expectancy or the lowest such improvement.

Figure 7 - Economic dependency ratios, 2008, and projections to 2050, medium improvement in life expectancy (\%)

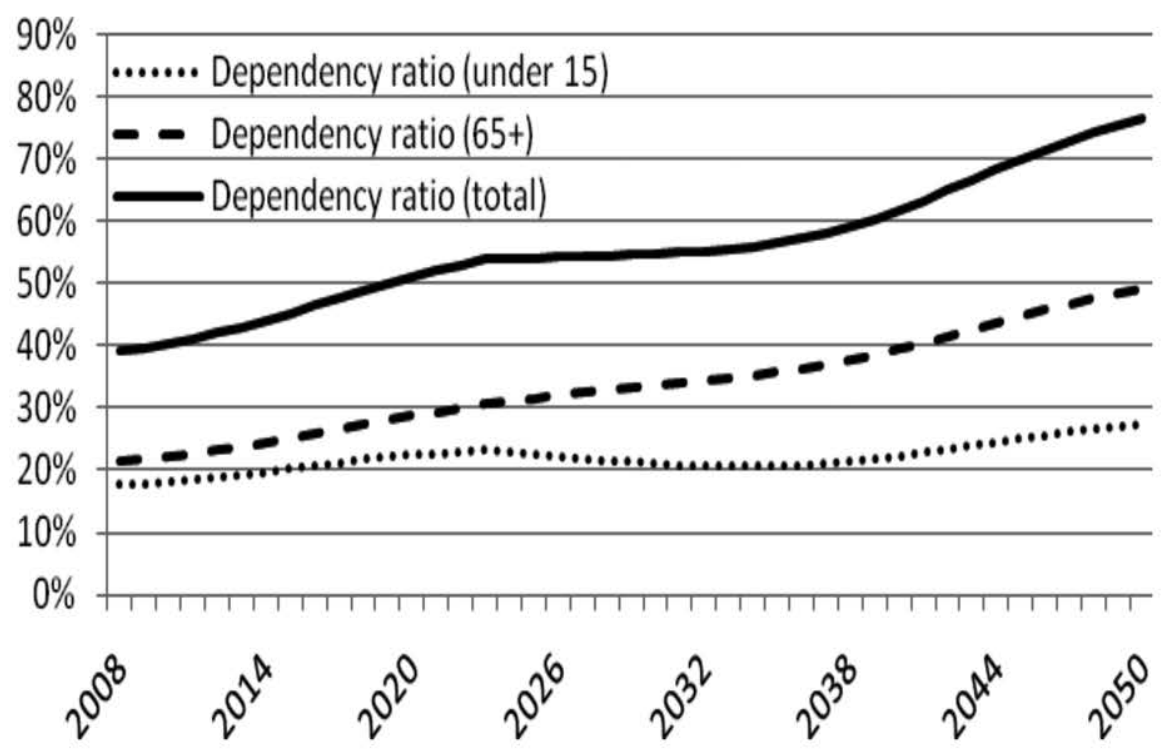

Table 5 - Dependency ratios, 2008, and projections to 2050 using alternative assumptions about improvements in life expectancy (\%)

\begin{tabular}{|l|c|c|c|c|c|c|c|c|c|}
\hline & $\mathbf{2 0 0 8}$ & $\mathbf{2 0 1 5}$ & $\mathbf{2 0 2 0}$ & $\mathbf{2 0 2 5}$ & $\mathbf{2 0 3 0}$ & $\mathbf{2 0 3 5}$ & $\mathbf{2 0 4 0}$ & $\mathbf{2 0 4 5}$ & $\mathbf{2 0 5 0}$ \\
\hline \\
\hline I variant - fast improvement of life expectancy \\
\hline Children (under 15) & 17.7 & 20.2 & 22.4 & 22.6 & 21.1 & 20.7 & 22.3 & 25.1 & 27.3 \\
\hline Adult (65 and over) & 21.4 & 25.1 & 28.9 & 31.9 & 34.2 & 36.6 & 40.7 & 46.5 & 51.6 \\
\hline Total & 39.1 & 45.3 & 51.3 & 54.5 & 55.3 & 57.4 & 63.0 & 71.7 & 78.8 \\
\hline II variant - middle improvement of life expectancy \\
\hline Children (under 15) & 17.7 & 20.2 & 22.4 & 22.6 & 21.1 & 20.7 & 22.3 & 25.1 & 27.2 \\
\hline Adult (65 and over) & 21.4 & 25.1 & 28.7 & 31.5 & 33.7 & 35.8 & 39.4 & 44.8 & 49.3 \\
\hline Total & 39.1 & 45.3 & 51.1 & 54.1 & 54.7 & 56.5 & 61.7 & 69.9 & 76.5 \\
\hline III variant - slow improvement of life expectancy \\
\hline
\end{tabular}




\begin{tabular}{|l|c|c|c|c|c|c|c|c|c|}
\hline Children (under 15) & 17.7 & 20.2 & 22.4 & 22.6 & 21.1 & 20.7 & 22.3 & 25.0 & 27.1 \\
\hline Adult (65 and over) & 21.4 & 25.0 & 28.5 & 31.1 & 32.9 & 34.7 & 37.9 & 42.9 & 46.8 \\
\hline Total & 39.1 & 45.2 & 50.9 & 53.7 & 53.9 & 55.4 & 60.2 & 67.9 & 73.9 \\
\hline
\end{tabular}

\section{Future growth in GDP}

The third, and very important, set of variables connected with macroeconomic performance in Bulgaria during the projected period includes real GDP, the GDP deflator and CPI (inflation). These aggregate indicators for the national economy determine how can we expect the Bulgarian economy to develop in the long-term. The dynamics of GDP growth projected in the future are of utmost importance because of the role of GDP as an independent variable in the ILO model.

The Bulgarian economy has achieved steady GDP growth over the last decade, from $5.4 \%$ in 2000 to $6.7 \%$ in 2004 , and around $6.0 \%$ in the following three years. The result of the current world economic crisis is that GDP saw a marked drop of $4.9 \%$ in 2009 , with zero growth in 2010. In the next few years, GDP growth should be faster as the country recovers from the crisis and as it continues the previous stable economic progress that has occurred subsequent to full membership of the EU (since 1 January 2007), as a result of access to the structural and cohesion funds and a more intensive inflow of foreign direct investment into the country. Up to the end of the projected period, however, we project lower GDP growth rates, which are more consistent with a policy of steady-state, balanced growth. The given assumptions are reflected in the dynamics of the rates of GDP growth and GDP per capita growth (see Table 6). Depopulation leads to GDP per capita growth rates being higher in comparison with total output growth.

Table 6 - Macroeconomic indicators for Bulgaria, 2008, and projections to 2050 (annual \% growth rates)

\begin{tabular}{|l|c|c|c|c|c|c|c|c|c|}
\hline & $\mathbf{2 0 0 8}$ & $\mathbf{2 0 1 5}$ & $\mathbf{2 0 2 0}$ & $\mathbf{2 0 2 5}$ & $\mathbf{2 0 3 0}$ & $\mathbf{2 0 3 5}$ & $\mathbf{2 0 4 0}$ & $\mathbf{2 0 4 5}$ & $\mathbf{2 0 5 0}$ \\
\hline Real GDP growth & 3.5 & 3.3 & 3.2 & 3.0 & 2.9 & 2.8 & 2.7 & 2.7 & 2.7 \\
\hline $\begin{array}{l}\text { Real GDP growth per } \\
\text { capita }\end{array}$ & 3.6 & 3.6 & 3.6 & 3.5 & 3.4 & 3.3 & 3.3 & 3.2 & 3.3 \\
\hline GDP deflator & 4.3 & 4.2 & 4.2 & 4.2 & 4.1 & 4.0 & 3.8 & 3.6 & 3.4 \\
\hline $\begin{array}{l}\text { CPI (inflation), annual } \\
\text { average }\end{array}$ & 4.9 & 4.7 & 4.5 & 4.4 & 4.2 & 4.0 & 3.8 & 3.6 & 3.4 \\
\hline
\end{tabular}

A sensitivity test of aggregate labour productivity to the changing age structure of the workforce

Given the ageing population in Bulgaria, in particular the changing number of working age, the final result that we are interested in is how this process affects aggregate labour productivity. Our calculations are based on the three alternative as- 
sumptions of improvements in life expectancy at birth and are given in Table 7. The basic findings are as follows:

1. there are small differences in projected GDP per worker in each of the three presented indicators of productivity: in absolute values, growth rates and indexes, in line with the three variants of improvement in life expectancy at birth. The differences between the results obtained using assumptions of medium and slow rates of improvement in life expectancy are smaller than those obtained by assuming medium and fast improvements

2. the faster the improvement in life expectancy at birth, the lower the growth of labour productivity, which means that our study confirms the negative effect of an ageing population on labour productivity

3. these calculations were performed a few years ago using a base year of $2003 \mathrm{and} /$ or 2005. It was expected, mainly because of the very long period of the projection and the studied number of the population, an indicator which changes relatively slowly (typical of inertness), that the obtained results - both as regards the level and, particularly, the trends outlined - would be as similar as the outcomes indeed indicate. In other words, there may be some differences in the specific numbers, but the main trends and conclusions are left intact. In general, the results show that the model is stable and relatively insensitive to small changes in the other main parameters.

\section{Conclusion}

Various published studies have indicated that it is difficult to estimate the impact of an ageing population and, in particular, an ageing workforce on labour productivity. In these studies, different approaches and methodologies are used but they do not provide an unconditional answer to the question of the impact of an ageing population on labour productivity. Obviously, work on this problem should continue.

The ILO model projections allow different scenarios depending on assumptions about future changes in the main economic and demographic indicators (in their capacity as independent variables). However, due to two main restrictions - namely the inevitable limitations of any model, and the near half-a-century projection frame, when a wide spectrum of changes in economic, social and demographic life could take place - the obtained results should be interpreted with caution. More important are the trends outlined rather than the precise estimates projected. In any case, these trends give useful insights for economic and social policy-makers.

Bulgaria has experienced a strongly deteriorating demographic situation in the past five decades and particularly from the beginning of the 1990s. The most negative features of this crisis are de-population and a rapidly ageing population. This population ageing is characterised by a low fertility rate and increasing life expectancy, resulting in a decreasing young dependency ratio and an increasing old age dependency ratio. These demographic processes have a lagging effect which predetermines their negative impact over the next several decades. According to even the most optimistic population projections for Bulgaria, the processes of ageing and de-population will accelerate in the first half of the $21^{\text {st }}$ century. 
The produced projections are also limited because they are simple extrapolations of current trends and ongoing economic and social processes. Policy-makers should also take into account probable policy decisions affecting technological progress and innovation, boosting GDP growth, as well as active policies towards the ageing of the population or the activation of the elderly: increased participation; enforced employability and working age (re-thinking retirement, because of longer living and longer learning and working); the development of a more favourable policy towards migration into the country; and more successful demographic policy (encouragement of births, longer life expectancy).

Table 7 - Labour productivity, 2008, and projections to 2050 under three assumptions of improvements in life expectancy

\begin{tabular}{|l|c|c|c|c|c|c|c|c|c|c|}
\hline & $\mathbf{2 0 0 8}$ & $\mathbf{2 0 1 5}$ & $\mathbf{2 0 2 0}$ & $\mathbf{2 0 2 5}$ & $\mathbf{2 0 3 0}$ & $\mathbf{2 0 3 5}$ & $\mathbf{2 0 4 0}$ & $\mathbf{2 0 4 5}$ & $\mathbf{2 0 5 0}$ \\
\hline Labour productivity - BGN (million) \\
\hline Slow & 10280 & 13484 & 16541 & 20487 & 25436 & 31506 & 38829 & 47698 & 57692 \\
\hline Middle & 10280 & 13481 & 16531 & 20464 & 25389 & 31422 & 38716 & 47578 & 57579 \\
\hline Fast & 10280 & 13478 & 16521 & 20443 & 25351 & 31377 & 38671 & 47505 & 57446 \\
\hline Productivity growth - annual rate of growth \\
\hline Slow & 4.19 & 4.02 & 4.27 & 4.43 & 4.40 & 4.31 & 4.25 & 4.13 & 3.67 \\
\hline Middle & 4.19 & 4.02 & 4.26 & 4.42 & 4.38 & 4.29 & 4.24 & 4.12 & 3.66 \\
\hline Fast & 4.19 & 4.01 & 4.25 & 4.41 & 4.38 & 4.30 & 4.24 & 4.12 & 3.65 \\
\hline Index of labour productivity (2008 & $\mathbf{1 0 0})$ \\
\hline Slow & 100 & 131 & 161 & 199 & 247 & 306 & 378 & 464 & 561 \\
\hline Middle & 100 & 131 & 161 & 199 & 247 & 306 & 377 & 463 & 560 \\
\hline Fast & 100 & 131 & 161 & 199 & 247 & 305 & 376 & 462 & 559 \\
\hline
\end{tabular}




\begin{tabular}{|c|c|c|c|c|c|c|}
\hline & 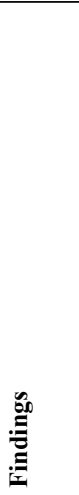 & 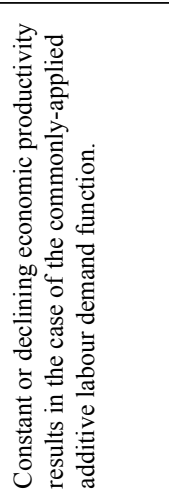 & 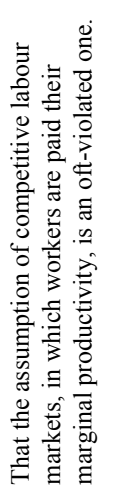 & 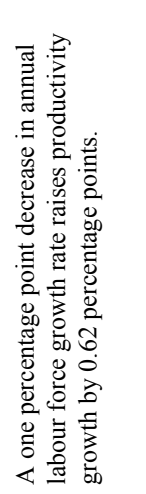 & 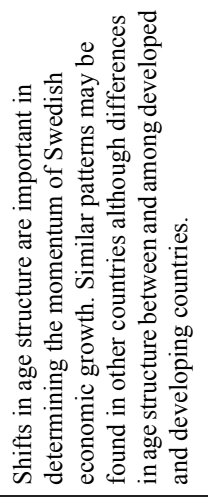 & 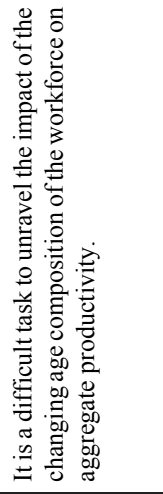 \\
\hline 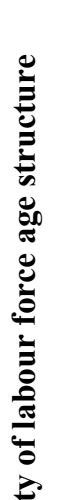 & 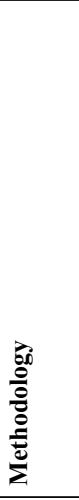 & 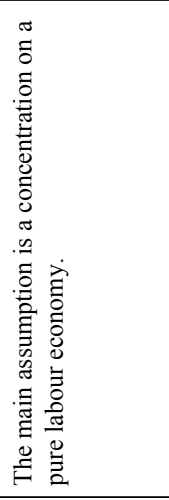 & 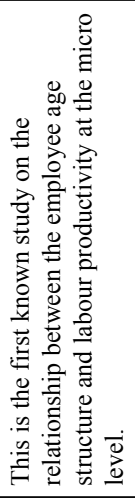 & 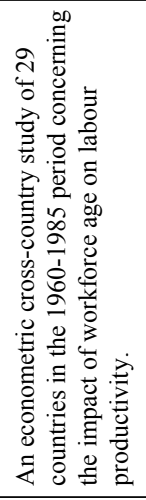 & 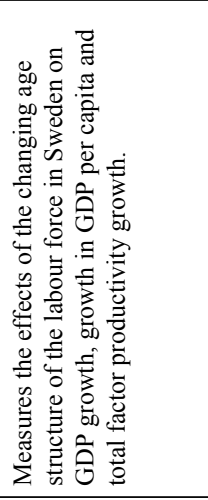 & 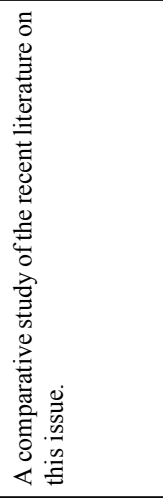 \\
\hline 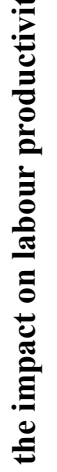 & 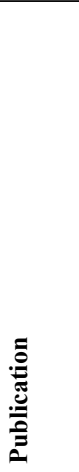 & 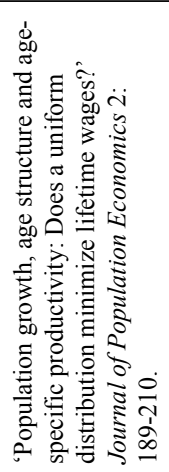 & 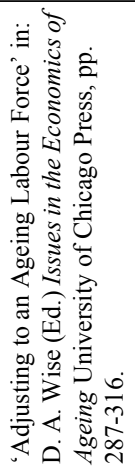 & 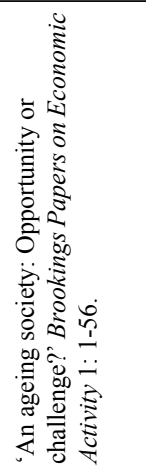 & 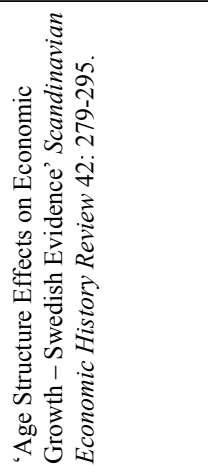 & 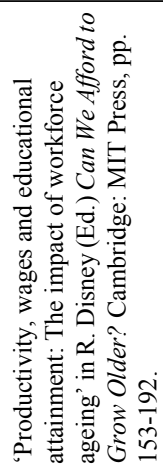 \\
\hline : & 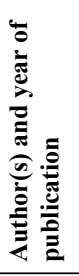 & 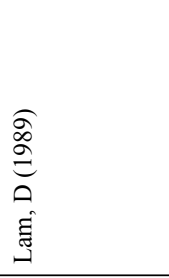 & 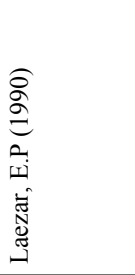 & 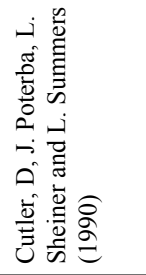 & 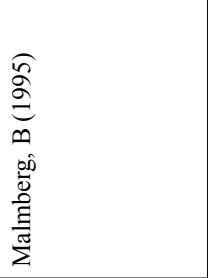 & 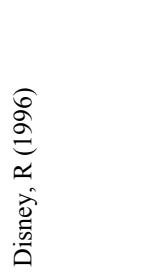 \\
\hline
\end{tabular}




\begin{tabular}{|c|c|c|c|c|c|c|}
\hline & 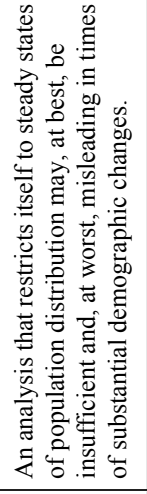 & 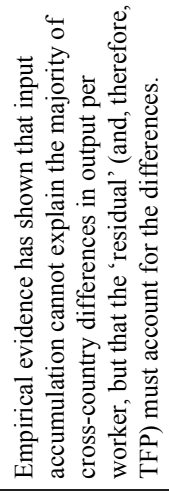 & 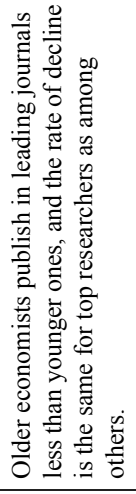 & 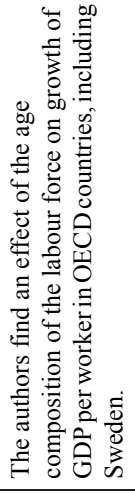 & 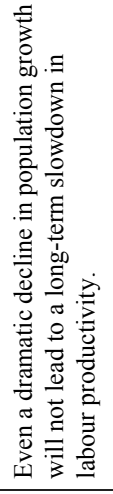 & 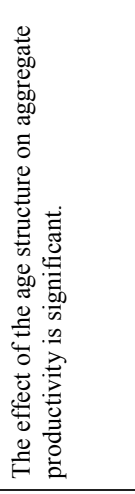 \\
\hline 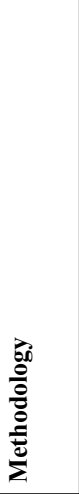 & 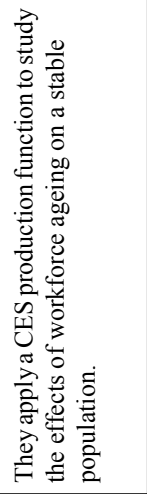 & 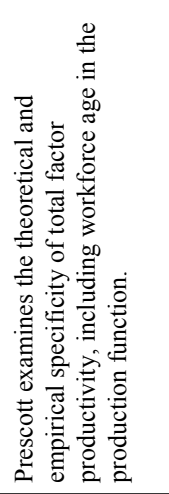 & 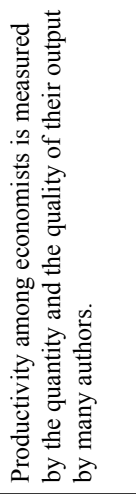 & 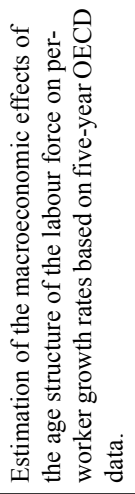 & 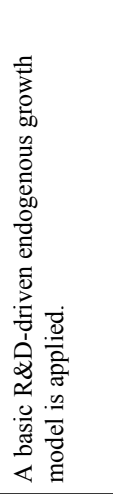 & 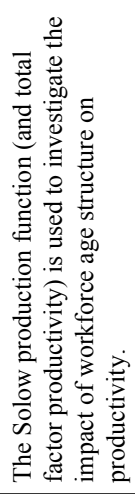 \\
\hline & 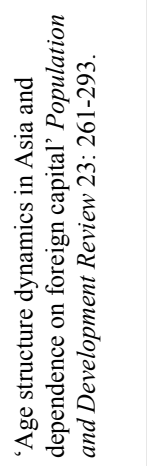 & 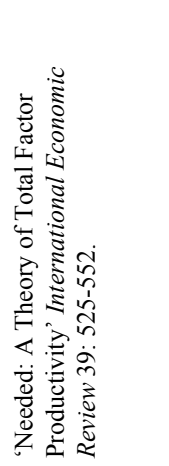 & 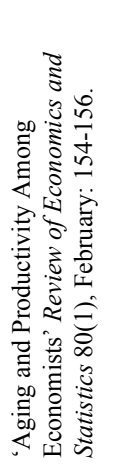 & 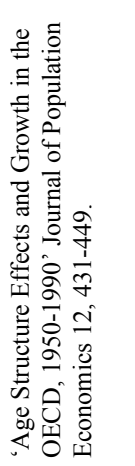 & 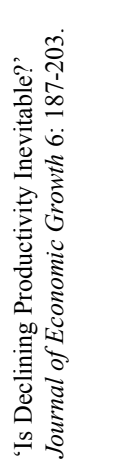 & 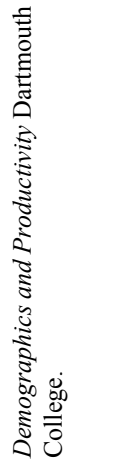 \\
\hline 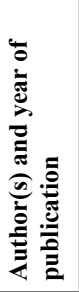 & 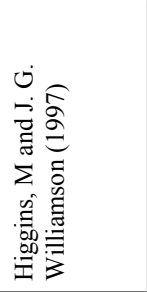 & 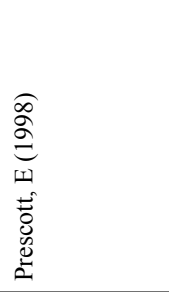 & 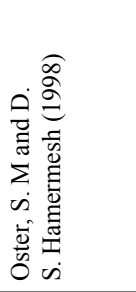 & 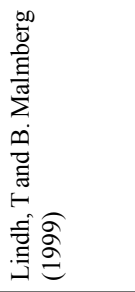 & 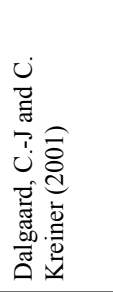 & 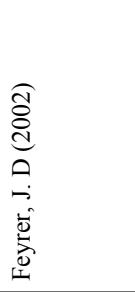 \\
\hline
\end{tabular}




\begin{tabular}{|c|c|c|c|c|c|}
\hline & 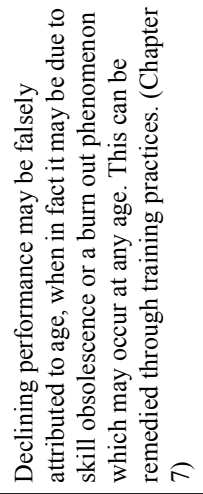 & 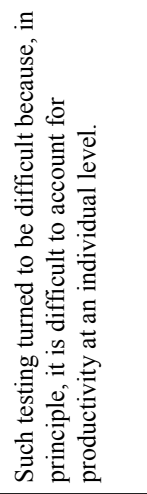 & 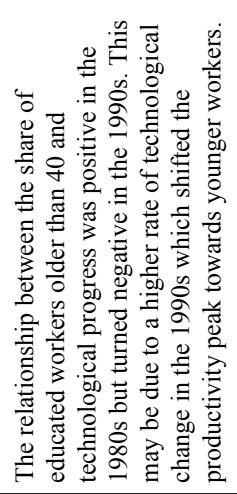 & 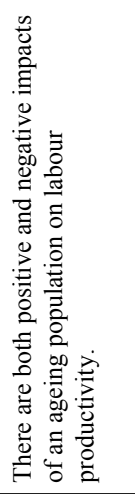 & 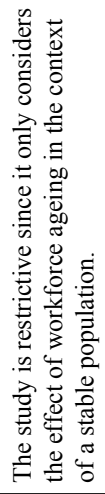 \\
\hline & 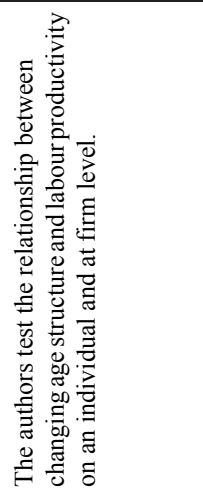 & 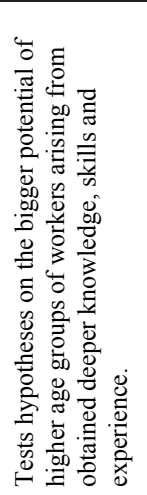 & 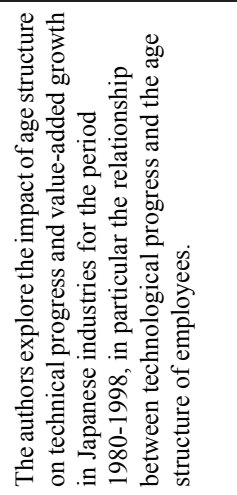 & 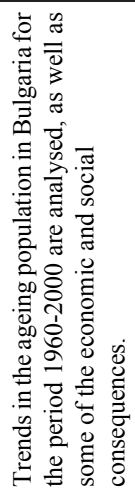 & 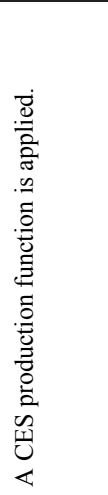 \\
\hline & 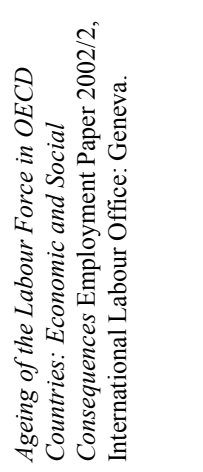 & 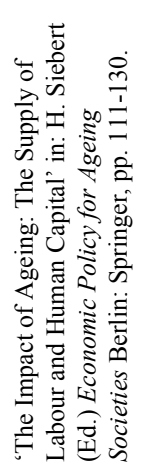 & 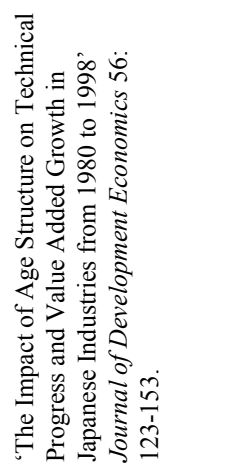 & 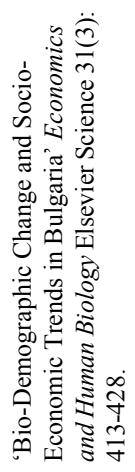 & 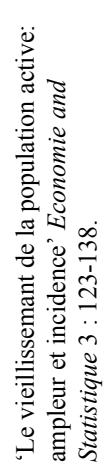 \\
\hline 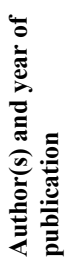 & 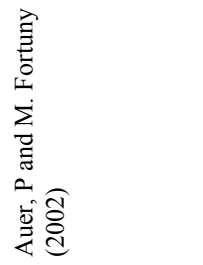 & $\begin{array}{l}\widehat{\Xi} \\
\text { d. } \\
0 \\
\text { : } \\
0 \\
\text { : } \\
0\end{array}$ & 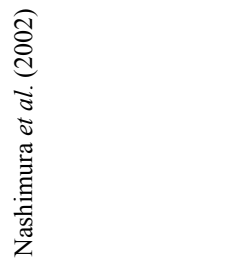 & 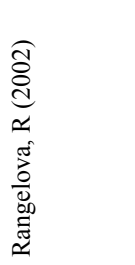 & 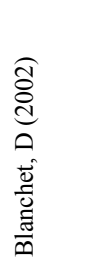 \\
\hline
\end{tabular}




\begin{tabular}{|c|c|c|c|c|}
\hline & 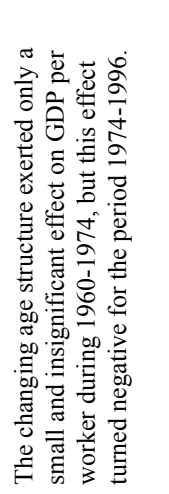 & 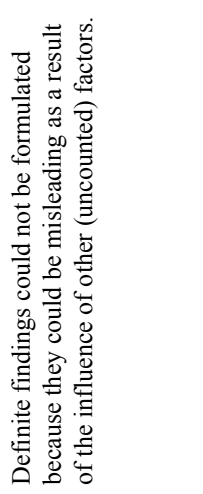 & 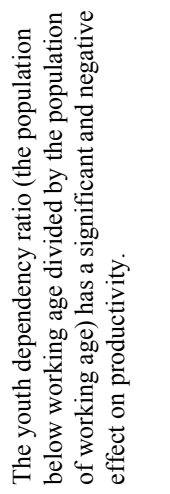 & 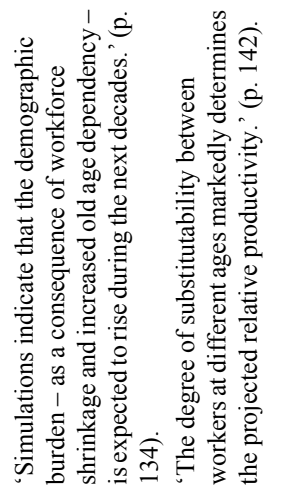 \\
\hline & 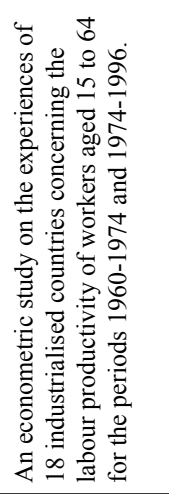 & 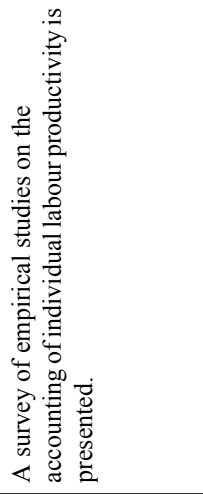 & 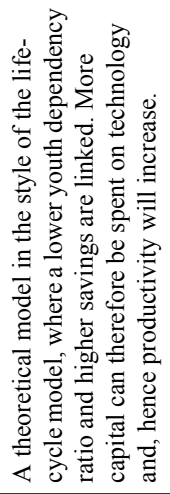 & 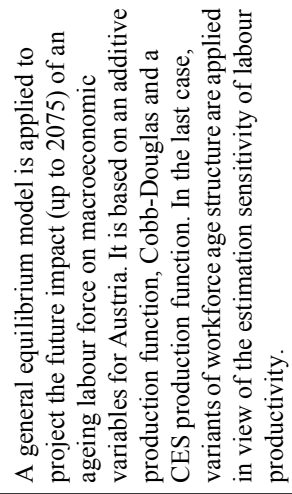 \\
\hline & 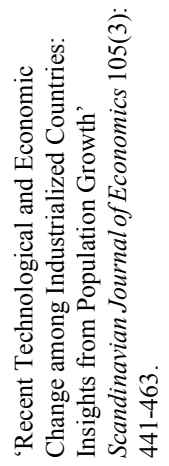 & 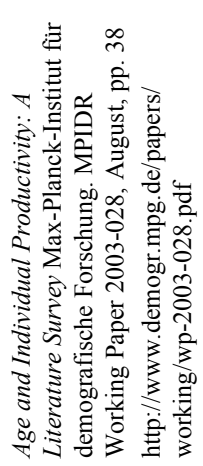 & 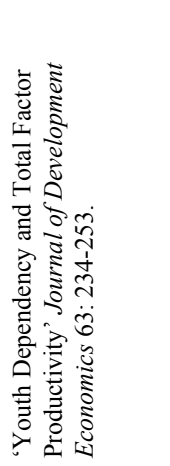 & 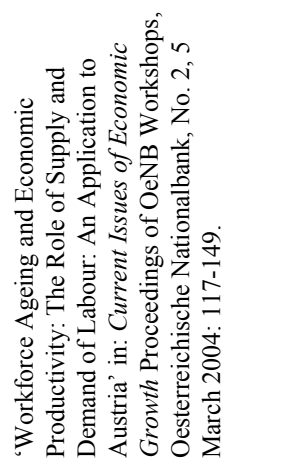 \\
\hline 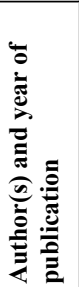 & 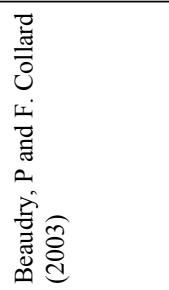 & 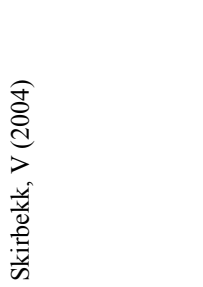 & 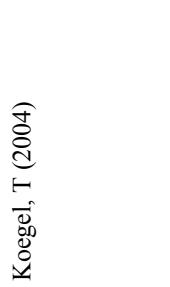 & 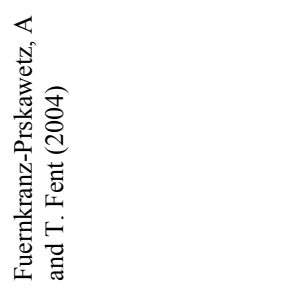 \\
\hline
\end{tabular}




\begin{tabular}{|c|c|c|c|}
\hline & 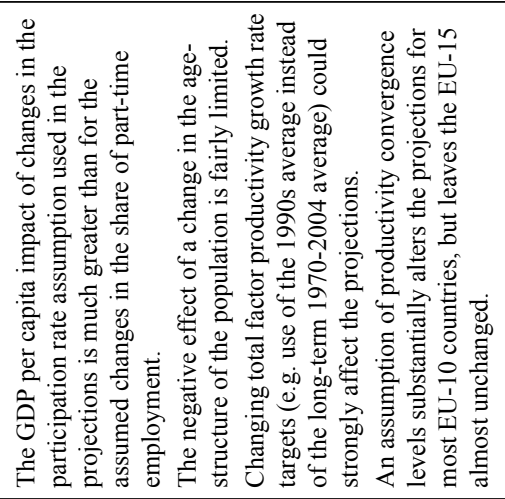 & 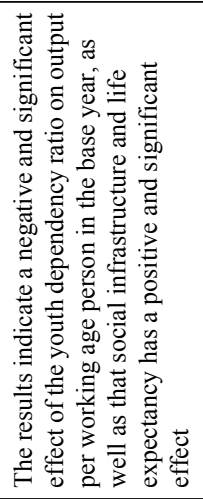 & 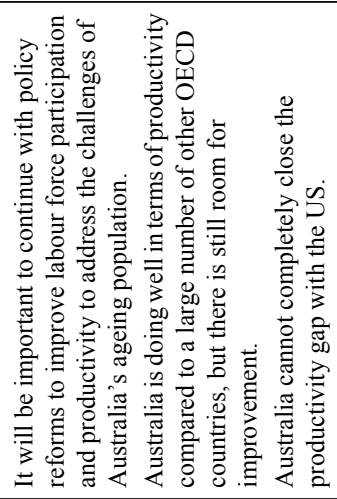 \\
\hline 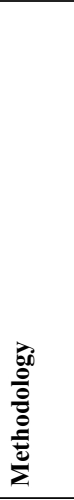 & 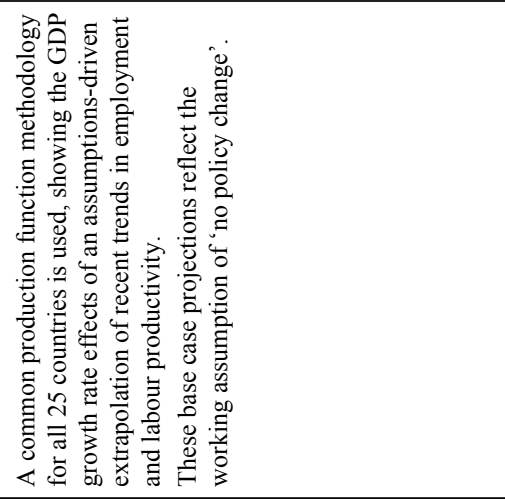 & 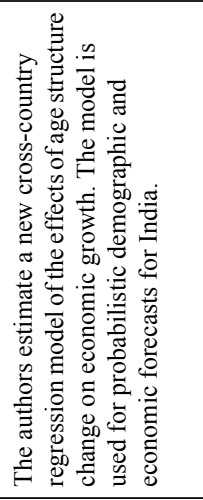 & 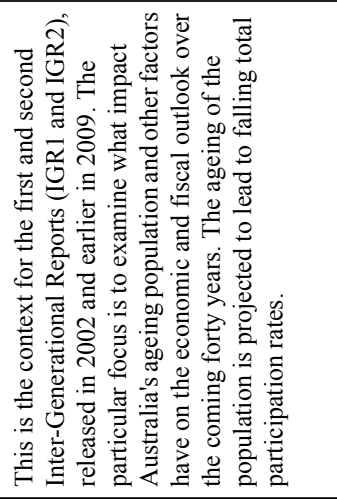 \\
\hline & 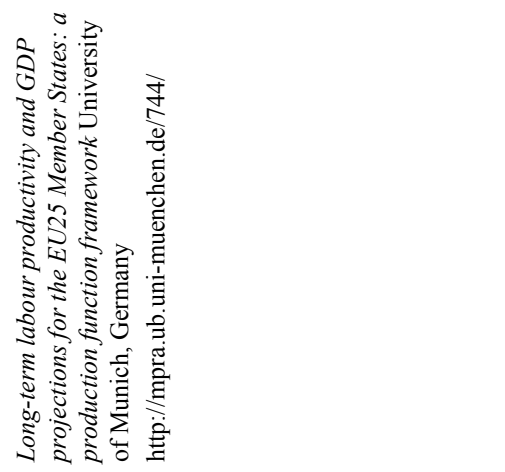 & 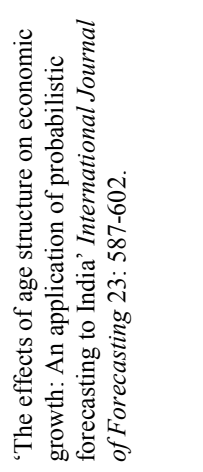 & 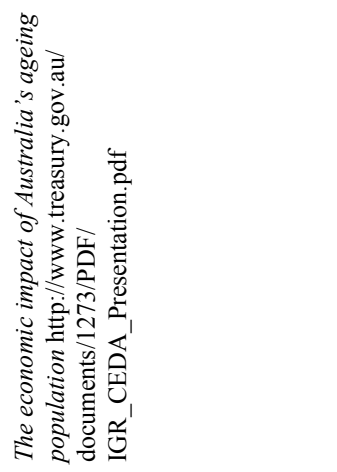 \\
\hline 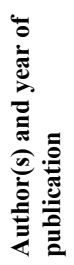 & 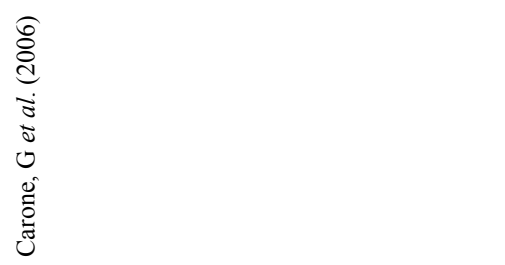 & 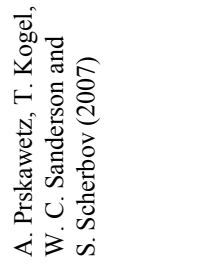 & 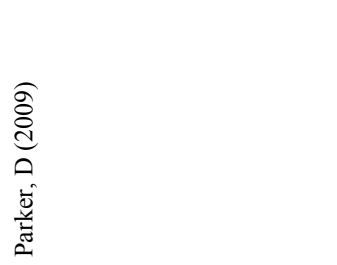 \\
\hline
\end{tabular}




\begin{tabular}{|c|c|c|c|}
\hline & & 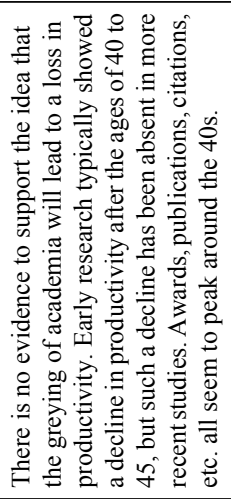 & 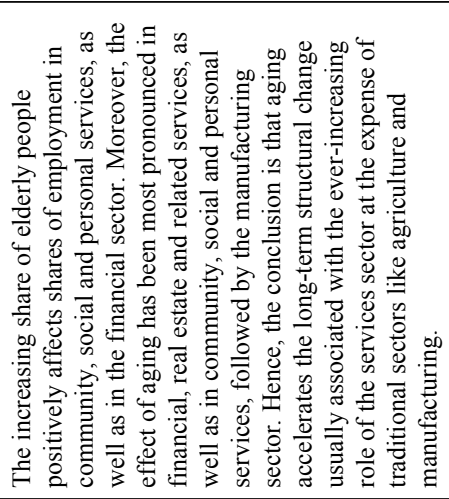 \\
\hline 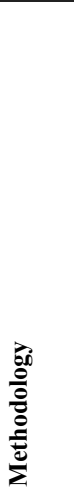 & 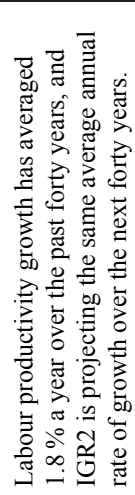 & 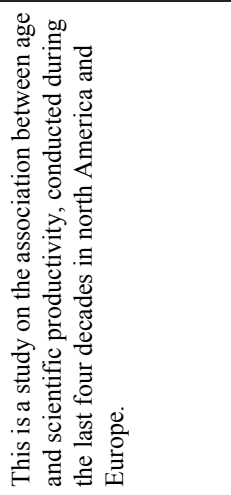 & 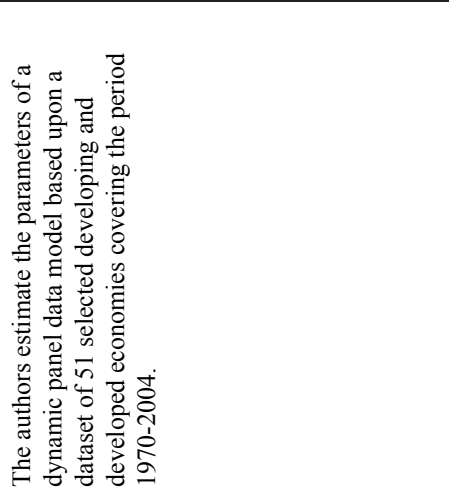 \\
\hline & & 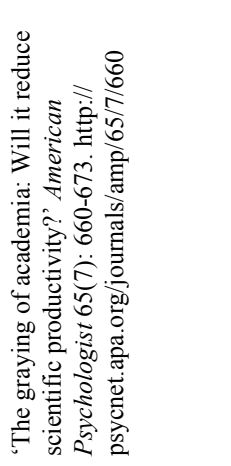 & 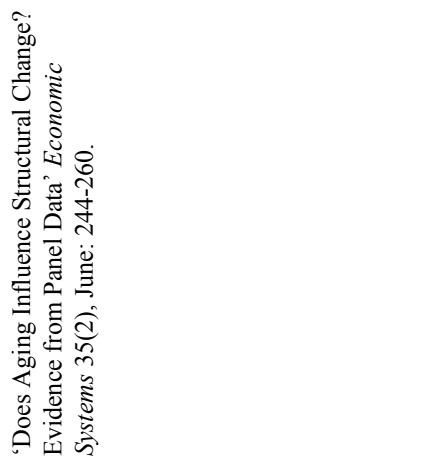 \\
\hline 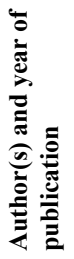 & & 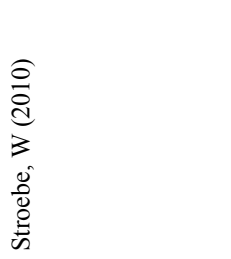 & 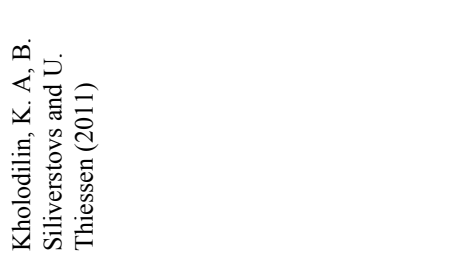 \\
\hline
\end{tabular}

